\title{
ABOUT PAIN AND ITS TREATMENT IN PARAPLEGICS
}

\author{
By M. Maury, M.D. \\ Centre de Rééducation Motrice, 77 зог Fontainebleau, France
}

\begin{abstract}
Apart from pains by removal of inhibition, there are pains by hyperstimulation as well, even with apparently complete paraplegia.

Successively, the author first reviews specific sub-lesional pains, then lesional pains (some of them are probably due to deafferentation), and at last, supra-lesional pains which are the most numerous ones and for which examples of hyperstimulation are given.

The therapeutic rules used by the author are enumerated. To ease their suffering about 8 per cent of the patients are given antidepressive drugs, which most of the time can be gradually stopped after several months.
\end{abstract}

Key words: Pains; therapeutic approach.

OwING to the neuro-physiologists, we know there are two kinds of pains, the ordinary physiological ones by hyperstimulation, and the neurological ones by removal of the inhibition, and it would be tempting to notice only neurological pains in paraplegics. We believe this would be a mistake since not only is there incomplete paraplegia but also we have no way of knowing whether in a so-called total paraplegia there are still possible connections between the peripheral receptors and the brain. Even after a very complete neurological examination, reviewing every sensitiveness on the whole sub-lesional territory, it is absolutely certain we can never maintain we have reviewed every possible stimuli, in their quality, intensity and localization. To find a cause may have some effect upon the treatment.

According to their topography, the paraplegic's pains can be classified in three categories: sub-lesional, lesional and supra-lesional categories.

With supra-lesional pains, the most important fact is to know that there might be pains which are felt at a distance, the most common one being the acute pain of the shoulder revealing the perforation of a gastric or duodenal ulcer with a tetraplegic who has previous digestive trouble. The treatment is then not the one of the pain.

The other pains particular to spinal cord injuries are the headaches of the autonomous hyperreflexia, the painful stiffness of the shoulder with the badly treated tetraplegics, which must be moved about, the dorsolumbalgia after an osteosynthesis which sometimes needs to be removed.

There are different kinds of lesional pains, i.e. pains in the proximity of the lesional level:

The hyperaesthesia has a variable topography, and is sometimes radicular. It is always near the border zone. Its treatment is difficult. It requires a very careful and reassuring approach to the patient who dreads the slightest contact and sometimes refuses any motion. The Jersey adapted to the limb or to the trunk decreases the contacts and may be sufficient to allow an increase of activities. Anxiolytics, even antidepressive drugs may be required. Fortunately these hyperaesthetical manifestations with time decrease or become more endurable.

Very close to them is the radicular pain, which is sometimes uncomfortable and very painful. Such pain may require the use of antidepressive drugs. It could possibly benefit from electro-analgesia about which we do not have any experience. One may ask if they are pains by deafferentation and to what extent a sectioning of 
the nociceptive ways by a selective posterior radicellotomia (under microscope and in one or two levels above the injury) should not be recommended. Obviously, it should be used only when the pain remains unbearable after a prolonged antidepressive treatment.

The pain of the cauda equina injuries, probably pain by deafferentation, is among those which have seemed to us as the most difficult ones to endure. Whether they are permanent or intermittent, their treatment is the same one as the one used for radicular pains.

Some of the lesional pain is provoked or exaggerated very much by immobility, such as pain of the elbow in the $\mathrm{C}_{7}$ injuries, of the knee or the tibial segment in $\mathrm{L}_{4}$ or L5 injuries. The motion stimulating the large fibres makes them disappear or at least greatly decrease; it must be intense enough to be efficient. Usually, the patients themselves discover this treatment and its right dosage, and use it.

We must also mention:

Pain by continuous press, at the top of the cyphosis following fractures. The examination clarifies the position in accordance with the sensitive border. It can be relieved by simply changing the press.

The diagnosis of muscular pain is sometimes difficult, with muscles such as the Latissimus Dorsi and the inferior Trapezius which to a great extent are sublesional and keep a supra-lesional innervation in the middle dorsal injuries. Rest and local infiltrations, if necessary, are generally sufficient.

In fractures pain is rather frequent. The vertebral motion recommended by Guttmann (1973) is not always easy. With loco-regional anaesthetic infiltrations and specially with time and some patience (it is the same approach as discussed later on), they never prove to be very uncomfortable for a long time.

Among the sub-lesional pains, which are the most numerous, those caused by hyper-stimulation are probably not the most frequent but there are some:

Pain by overstretching of the vascular envelopes. Posture has a great effect upon them. They are accompanied by oedema. The most efficient treatment consists of lying down for I or 2 hours in the middle of the day. Pain which sometimes occurs with the beginning of a para-osteo-arthropathy, and which we have even noticed in the apparently complete injuries, must be classified in the same category.

Visceral pain. They are more unusual than one could expect, considering the frequency of the gaseous distensions and the ano-rectal complications with the paraplegic. We must say that with the normal patient, the amount of painful ano-rectal complication is very low. However, when paraplegics grow older and possibly with a more careful search for decompensation at the intestinal level, one can notice some complications beyond the ano-rectal area: sigmoiditis combined sometimes with megacolon, bringing pain, which late appearance and vague localization arouse one's attention to the intestine. We wish we could find a relationship between the perception of the visceral pain and the lesional level. In fact, this relation seems to be impossible due to the fact that there is no individualised interoceptive way, and also because some impulses can spread through the periarterial plexus and through the paravertebral sympathetic ways.

Pain with increase of spasticity. It is curious to notice the similarity between pain and spasticity on neuro-physiological aspect. Some patients talk about painful spasms, when in fact they don't have any reflex functions, others talk about pain when only their spasticity makes them feel uncomfortable.

When the interview stipulates that the pain increases with the spasticity, a cause must be looked for and sometimes can be found, for instance coxarthrosis, sacroiliac-arthrosis. When this cause is known and localised, and does not prove to be 
accessible to the treatment (e.g. lumbar arthrosis), and the distress seems too important, we can think of a selective posterior radicellotomy which-dealing with two or three roots-can eliminate the nociceptive afferent.

Finally the precordial pain is a sub-lesional one in tetraplegics. It can be an isolated manifestation of a moderate autonomous hyperreflexia and, for instance, maintained by a catheter or a badly tolerated 'cystocath'. A changing of this equipment may be sufficient to make it disappear.

Various authors have pointed out a relationship between bedsores and pain. Having seen many patients who are not suffering or suffering very little from their sores, we feel that this relationship is due to a wrong nursing procedure during the first weeks and to imposed prolonged inactivity.

At last, the sub-lesional pains, properly neurological ones, are therefore only explained by the removal of the inhibition, at least until now. For, from certain clinical observations, we are convinced the dismemberment of these pains is far from being achieved. The osteoporosis (a source of pains among old people) possibly plays a part with our patients as well. Some paraplegics with fever pains, which sometimes become unbearable in the lower limbs, call to mind the role of the prostaglandins and that the humoral way must not be forgotten.

The therapeutic approach first of all proceeds from a general attitude, based on some elementary rules:

-always listen carefully to the patient's complaint,

-whatever are the descriptions, the mimics, the repetitions, never mock the patient.

- use with great care the 'psychological label', which often has a derogatory meaning.

-at least during the first few months, explain to the patient that pain is linked to the neurological state and that one can hope for a decrease with the increase of activity: the normal man who is suffering from a pain such as toothache will not suffer much and sometimes will even forget about his pain if his mind is occupied with conversation, reading or any diversion which interests him.

-during the round or the consultation, never be the first to mention the pain. - later on before the patient's discharge, let the paraplegic know about the risks he is running in multiplying the consultations and the search for therapeutic advice: danger of drugs with their toxicity, tolerance, influence upon natural inhibitions, risks of useless surgery. Leave a door opened to a consultation with a specialist (neurosurgeon) during the next check-up.

-give the smallest possible amount of medicine, and never leave the dosage to the patient's liking; strictly forbid any opiate, start with the most gentle ones such as Glifanan, Duperan.

When the pain seems to be too difficult to bear, it is recommended to use antidepressive drugs usually associated with a neuroleptic one, while watching their secondary effects, especially on blood pressure and on the contractility of the detrusor. This therapeutic does not modify the pain but only the way it is endured, and it has been without any doubt an important contribution. Table $\mathrm{I}$ is made from the data of the last 200 patients after discharge (I00 in the first stages and 100 in check-up). It gives an idea of the frequency of the use of the medications in our unit. One can notice that 8 per cent of the recent patients and 3 per cent of the late patients profit from an antidepressive treatment for their pain. Only one patient, out of the three check-ups who kept on getting this treatment, should have had a neuro-surgical consultation.

When the biochemical future of the problem of pain seems promising, we think it is useful to finish with points which seem to be the most important with the paraplegic: the search for a cause even when the paraplegia is apparently 
complete, the special therapeutic approach, the importance of a permanent activity which is all the more efficient as it is motivated.

TABLE I

\begin{tabular}{|c|c|c|c|}
\hline $\begin{array}{l}\text { Number of } \\
\text { patients }\end{array}$ & Anodyne drugs & $\begin{array}{l}\text { Antidepressive } \\
\text { drugs }\end{array}$ & Neuro-surgery \\
\hline Ioo First stays & $4^{\star}$ & $8 \dagger$ & 0 \\
\hline Ioo Check-ups & I & 3 & ०? \\
\hline
\end{tabular}

\section{RÉSUMÉ}

A côté des douleurs par levée de l'inhibition, il y a aussi chez le paraplégique des douleurs par hyperstimulation, même dans des lésions apparemment complétes.

Les auteurs revoient successivement les douleurs sus-lésionnelles, puis lésionnelles (une partie d'entre elles est probablement due à la déafférentation), enfin les douleurs souslésionnelles qui sont les plus nombreuses et parmi lesquelles sont donnés des exemples de douleurs par hyperstimulation.

Les auteurs énoncent leurs régles thérapeutiques. Environ 8 per cent de leurs malades bénéficient d'un traitement anti-dépresseur qui dans la majorité des cas peut être ârreté avant la sortie.

\section{ZUSAMMENFASSUNG}

Neben den durch die Aufhebung der Inhibition verursachten Schmerzen, gibt es bei dem Querschnittgelähmten, selbst bei scheinbar völliger Schädigung, Schmerzen durch Uberreizung.

Die Verfasser unterscheiden folgende auftretende Schmerzen: Oberhalb der Rücken marksverletzung, in der Höhe der Rückenmarksverletzung (ein Teil unter ihnen entsteht wahrscheinlich durch die 'Deafferentation') und schließlich, Schmerzen unterhalb der Rückenmarkverletzung, die zu den häufigsten zählen und unter denen auch die Beispiele der Uberreizungsschmerzen $\mathrm{zu}$ verzeichnen sind.

Die Verfasser sprechen über ihre therapeutischen Erfahrungen. Ungefähr 8 percent ihrer Kranken erhalten eine Behandlung mit Beruhigungsmitteln, die in den meisten Fällen vor der Entlassung beendet werden kann.

\section{REFERENCES}

Botterell, E., Callaghan, J. C. \& Jousse, A. (1954). Pain in paraplegia: clinical management and surgical treatment. Roy. Soc. Med., 47, 28I-288.

Burke, D. C. (1973). Pain in paraplegia. Paraplegia, 10, 297

Castellano, V. (I97I). Problems of analgesic therapy in traumatic paraplegia. Proceedings of the Eighteenth Veterans Administration Spinal Cord Injury Conference, p. I89.

Grossiond, A. \& PANNiER, S. (I966). La douleur chez les paraplégiques. 4ème Congrès international Med. Phys. Paris. Excerpta Med. Ed.

Guttmann, L. (1973). Spinal Cord Injuries: Comprehensive Management and Research. Blackwell Scientific Publications, Oxford.

Hazouri, J. \& MUELler, A. D. (I950). Pain threshold studies on paraplegic patients. Arch. Neurol. and Psychiatry, 64, 607.

Mamo, H. (1968). La Douleur. Baillière ed., Paris.

Mamo, H. (I976). Bases neurophysiologiques de la douleur. La Vie Médicale, 40/4I, 3247.

Mazars, G. (1976). Etat actuel de la chirurgie de la douleur. Neuro-chirurgie, 22, 437.

Michaelis, L. S. (I970). The problem of pain in paraplegia and tetraplegia. Bull. N.Y. Acad. Med., 46, 88.

Mueller, A. D. (1962). Pain studies of paraplegia patients. Arch. Neurol. Chicago, 7, 335.

Sindou, M. (1976). Neurochirurgie de la douleur. La Vie Médicale, 40/4I, 3283. 